\title{
Tags de cor para identificação de cenas animadas em roteiro, Storyboard e Animatic
}

Color tags for identifying animated scenes in script, Storyboard and Animatic

\section{Cíntia Cardoso}

Universidade Federal de Santa Catarina

cintia.animationdesigner@gmail.com

X

Wiliam Machado de Andrade

Universidade Federal de Santa Catarina

w.andrade@ufsc.br

Flávio Andaló

Universidade Federal de Santa Catarina

fla2@uol.com.br

Milton Luiz Horn Vieira

Universidade Federal de Santa Catarina

milton.vieira@ufsc.br

Gustavo Eggert Boehs

Universidade Federal de Santa Catarina

gustavo.boehs@ufsc.br

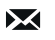

PROJËTICA

\section{COMO CITAR ESTE ARTIGO:}

CARDOSO, Cíntia; ANDRADE, Wiliam Machado de; ANDALÓ, Flávio; VIEIRA, Milton Luiz Horn; BOEHS, Gustavo Eggert. Tags de cor para identificação de cenas animadas em roteiro, Storyboard e Animatic. Projética, Londrina, v. 11, n. 2, p. 255-280, 2020.

DOI: 10.5433/2236-2207.2020v11n2p255

Submissão: 30-09-2018

Aceite: 07-05-2019 
Projética, Londrina, v. 11, n. 2, p. 255-280, agosto 2020

RESUMO: A indústria brasileira de animação passa por momento de estímulos para sua produção, mas as oportunidades de financiamento e exibição não ponderam acerca dos métodos que cada estúdio utiliza para desenvolver as obras. O presente artigo traz uma proposta, por meio de tags de cor, de integração de três momentos da pré-produção (roteiro, storyboard e animatic), apresentando uma alternativa de identificação de trechos planejados nessas etapas, buscando economia de tempo ao conectar estratos narrativos de diferentes fases.

Palavras Chave: Tags de cor. Animação brasileira. Pré-produção.

ABSTRACT: The Brazilian animation industry is going through a period of production stimulation, but the financing and exhibition opportunities do not reflect on the methods that each studio uses to produce the works. This article presents a proposal, by means of color tags, for the integration of three pre-production moments (script, storyboard and animatic), presenting an alternative for identifying planned sections in those steps, aiming to save time by connecting narrative excerpts in the different phases.

Keywords: Color tags. Brazilian animation. Pre-production.

\section{INTRODUÇÃO}

A indústria da Animação, no Brasil, vem demonstrando crescimento contínuo nos últimos anos, chegando a ter seu momento presente de produção classificado como "boom" de lançamentos tanto de produtos voltados ao cinema quanto aqueles destinados à TV. (BRASIL, 2018). 
Tal quadro pode ser explicado pelas atuais condições de fomento e exibição das obras nacionais, amparadas por aparato legal com tal fim, como as leis 12.485 de 2011 (que prevê cotas de veiculação em acesso condicionado), a Rouanet, a do Audiovisual e a programas e editais organizados e geridos por iniciativas como 0 Fundo Setorial do Audiovisual (FSA).

Observa-se, entretanto, que a seleção de propostas para captação de recurso ou garantia de espaço de exibição está voltada a análises curriculares dos realizadores e das abordagens narrativas dos projetos, sem que seja apontado como critério formas de gestão utilizadas pelos estúdios para o adequado cumprimento das obrigatoriedades listadas em candidaturas de qualquer estímulo público.

Resta aos criadores e produtores encontrarem suas próprias formas de planejar e conduzir prazos, recursos e organização interna, sabendo-se tratar de uma indústria jovem, desprovida de conhecimento acumulado ao longo dos anos por experiências próprias, como em polos produtivos consolidados (por exemplo, Estados Unidos, Canadá, França e Japão).

Assim sendo, e tendo em vista que a literatura acerca do assunto é predominantemente estrangeira e baseada em equipes cujos números de profissionais que as formam não podem ser equiparados à realidade brasileira, métodos voltados à eficiência precisam ser elaborados de formas inovadoras, a fim de compensar criativamente o que financeiramente não é possível executar como reprodução do que é descrito nos relatos e guias de outros países.

Dentre as divisões que levam à produção de obra animada, desde seu início até o fim, o presente artigo tem como objetivo apresentar uma proposta, baseada em ferramentas do design, para a etapa que envolve a produção do storyboard, bem como seu vínculo com os processos anteriores e posteriores de sua execução, visando aprimorar sua visualização e relação com o seu texto de origem (o roteiro) e com o animatic (sua edição para reprodução em vídeo). 
Desta forma, pretende-se prover aos produtores brasileiros uma alternativa de pensar o processo de constituição de uma obra de forma integrada e que permita economia de tempo a cada vez que uma alteração se mostre necessária durante a produção animada.

\section{A ANIMAÇÃO, O STORYBOARD E O ANIMATIC}

Apesar da animação ser considerada uma forma de arte, ela não é uma forma de arte de um único realizador. Um grupo de artistas é necessário para completar um filme animado com a qualidade adequada para sua exibição. Além disso, a animação é, normalmente, um processo custoso tanto em questões financeiras quanto em questões de tempo e qualquer elemento que facilite esse processo, conforme White (1988), não deve ser ignorado.

Tal processo de desenvolvimento completo de uma animação é dividido nas seguintes fases, conforme Winder e Dowlatabadi (2011, tradução livre dos autores): 1) Desenvolvimento (onde a equipe principal começa a ser montada); 2) Preparação (a equipe continua sendo montada, e são identificados locais de trabalho, tecnologias a serem utilizadas, assim como o método de produção e os seus procedimentos); 3) Pré-Produção; 4) Produção; e 5) Entrega.

A terceira fase, de pré-produção, é o momento em que são elaborados os elementos fundamentais para a produção da animação, podendo ser dividida em três processos-chave que a fundamentam (cf. BYRNE, 1999): o roteiro ou script, o storyboard, e o animatic ou story reel.

Segundo White (2006), a pré-produção apresenta a possibilidade de testar, editar e cronometrar a narrativa audiovisual, pois isso permite ter uma impressão do projeto antes que ele realmente comece a ser executado. Sendo assim, é possível saber aquilo que pode ser melhorado para que se alcance resultado eficaz e positivo. 
Ainda segundo esse autor, embora alguns animadores sem experiência e alunos calouros insistam que storyboards consomem muito tempo e os considerem supérfluos, praticamente todos os projetos profissionais, não importa o tamanho, são meticulosamente desenhados em quadros antes da produção. O storyboard não é apenas uma obra de arte, é também um modelo esquemático daquilo que será cobrado da equipe de animação. Além disso, um storyboard bem executado é uma valiosa ferramenta para os produtores, contadores e controladores de orçamentos saberem onde o dinheiro será gasto e por que ele será gasto.

Trata-se de uma versão desenhada que prevê o produto, cujo objetivo é dar uma pré-visualização daquilo que a história poderia ser como um filme. Um storyboard começa de um texto, o roteiro, onde o artista que irá desenvolvê-lo transforma aquilo que está escrito no roteiro em imagens, no formato de quadros sequenciais.

Esses quadros são expostos para que possam ser explicados, num processo denominado como pitch, para o diretor e outros membros da equipe, de modo que sejam revisados durante o processo criativo de desenvolvimento do storyboard. Somente depois que for considerado adequado é que será editado em uma versão animada (o animatic), sendo acrescentadas vozes aos desenhos, assim como efeitos sonoros e uma trilha sonora temporária que transmita a emoção desejada para o momento. Essa versão com desenhos é assistida e retrabalhada quantas vezes forem necessárias para que a história seja contada da melhor forma possível.

O animatic, segundo White (2006), além de permitir visualizar quais são as deficiências na forma como a história está sendo contada para corrigi-las antes que a produção da animação seja iniciada e tempo e dinheiro sejam gastos com um projeto ineficaz, permite que a equipe inteira possa visualizar e compreender aquilo com que irá trabalhar. 
Tanto o storyboard quanto o animatic são frutos de uma sequência de operações reiterativas e contínuas realizadas em conjunto pelos membros da equipe responsáveis por atuar nesses processos-chave, dentre eles diretor, roteirista, artistas e produtor. A lapidação de ambos só é possível devido à constante comunicação entre o grupo.

Comunicação é um instrumento central no desenvolvimento da animação, uma vez que ela relaciona as pessoas, tecnologias e processos. De acordo com Teixeira (2015), um sistema de informação qualificado, padronizado e de fácil uso possibilita que a informação sobre a atividade seja capturada e incorporada no processo de desenvolvimento do projeto orientando os envolvidos, colaboradores e gestores. A visualização do processo pela equipe de maneira que possibilite comparações, localização de padrões e mapeamento de ideias torna o grupo e o projeto mais eficiente e eficaz.

A falta de entendimento, falhas de comunicação e erros de interpretação prejudicam a produtividade do projeto. Essas fragilidades podem ser superadas com melhorias, tais quais inovações e sistematização na hora de promover a informação, que necessita ser integrada no processo de desenvolvimento do projeto. Durante a pré-produção de animação, tanto no roteiro quanto no storyboard e animatic a análise e o diálogo entre a equipe são feitos com foco a divisão das cenas.

Problemas durante a pré-produção puderam ser identificados em pesquisas exploratórias bibliográficas que compõem este trabalho, bem como experiências próprias, que apontam uma deficiência na comunicação entre a equipe devido à forma que as cenas são identificadas no storyboard e animatic, causando uma falha na comunicação pode trazer à tona a falta de entendimento e erros de interpretação referentes a qual trecho um membro do grupo menciona para os demais no decorrer do processo de refinamento do storyboard e do animatic. 
Observando como progridem em suas operações, tecnologias e pessoas que englobam; tais quais suas respectivas importâncias em questões financeiras, práticas, orientadoras e organizacionais como fundamentos para o progresso de animação, o presente trabalho procurou desenvolver e aplicar um sistema de identificação de cenas com o intuito de melhorar o processo produtivo durante a préprodução. A alternativa encontrada foi um sistema de tags de cores que procurou contornar a falta de entendimento e erros de interpretação na identificação de cenas e na comunicação entre a equipe. As tags de cor foram sistematizadas de forma adaptável, permitindo o fluxo e o processamento de informações entre os envolvidos na criação do storyboard e do animatic.

\section{PESQUISA}

O levantamento bibliográfico, em forma de revisão sistemática, sobre obras voltadas à produção de animação realizado para o presente artigo, buscando conteúdos ligados aos termos storyboard, animatic e roteiro (script, scriptwriting ou screenplay) coletou quarenta livros que versam sobre as diferentes fases e técnicas que envolvem desde a pré até a pós-produção e finalização de uma obra.

Dessas, conforme a tabela abaixo, dezenove abordavam diretamente pelo menos dois dos termos, trazendo definições ou orientações acerca da utilização e papel no contexto geral de produção.

Organizados em uma tabela sobre potenciais modelos ou padrões de conexão no planejamento entre roteiro, storyboard e animatic, bem como a "Conexão entre os trechos", onde foi identificado se havia qualquer indicação entre os documentos que estabelecesse correspondência entre os mesmos momentos descritos no roteiro, no storyboard e no animatic. A tabela pode ser observada a seguir: 
Projética, Londrina, v. 11, n. 2, p. 255-280, agosto 2020

늠

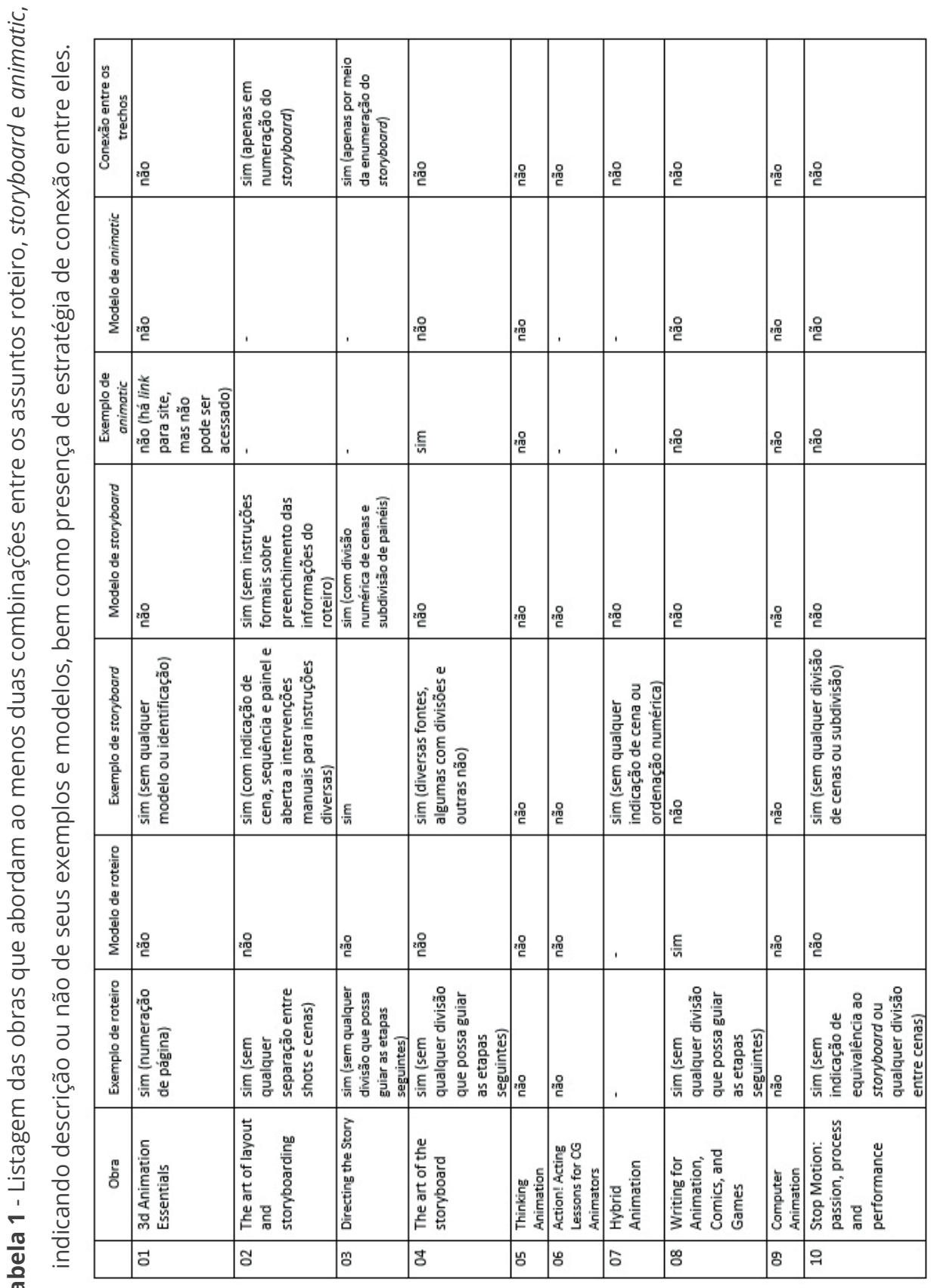

点 
Tags de cor para identificação de cenas animadas em roteiro... Animatic CARDOSO, C. et al

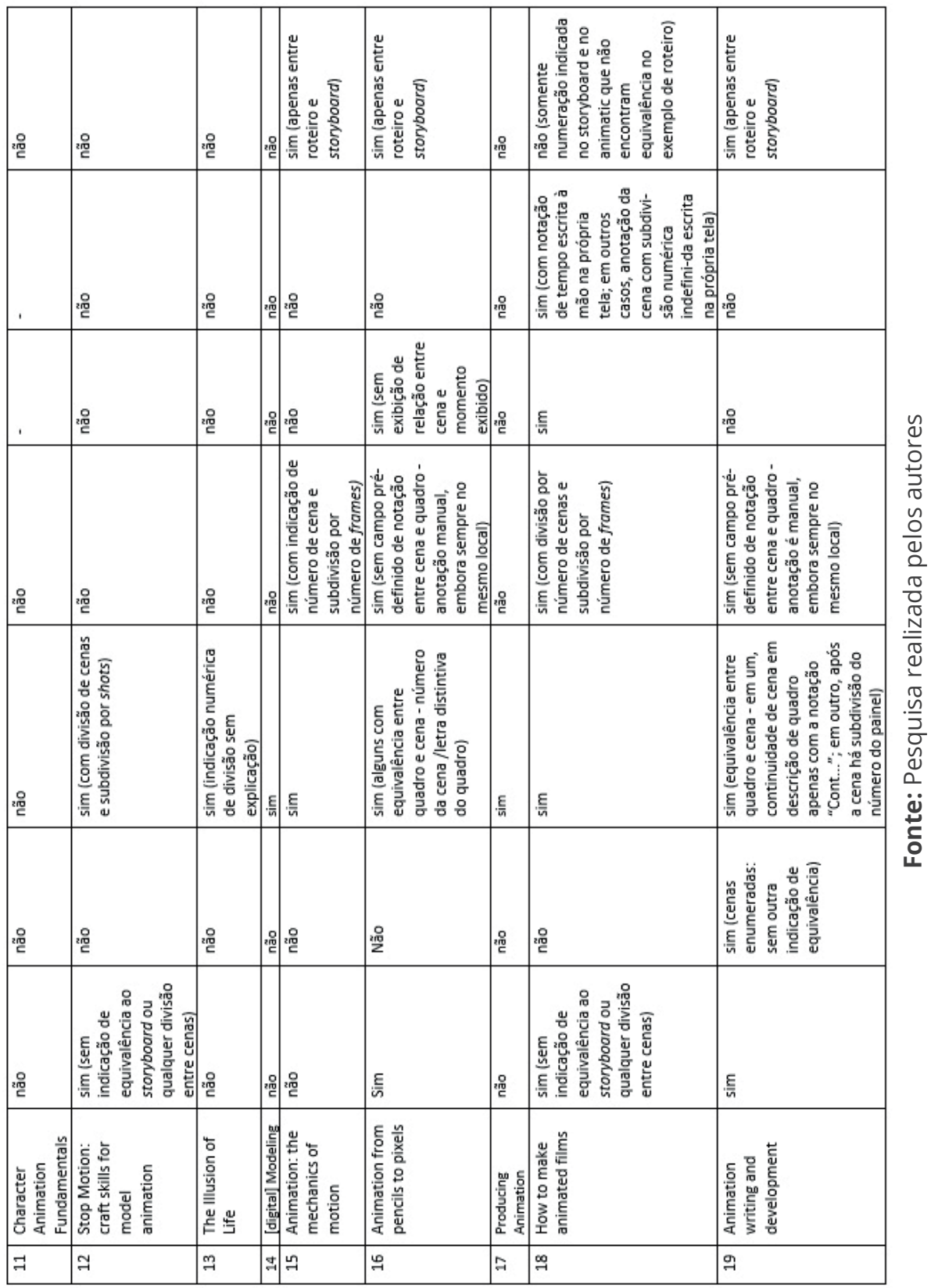

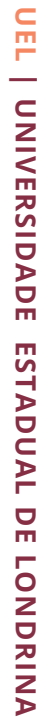


Como pode ser concluído pela leitura dos resultados, não há na literatura a preocupação em sistematizar o fluxo de informação de maneira integrada relacionado a uma cena ou shot, tornando a identificação de partes específicas de uma determinada obra um trabalho, possivelmente, consumidor de tempo que poderia estar voltado a outras atividades. Mesmo quando há indicação numérica, não há evidência dessa marcação nos materiais distribuídos durante a préprodução, exigindo dos profissionais leituras e profundo conhecimento da obra para tentar encontrar as correspondências.

Num contexto de longa-metragem, por exemplo, onde o volume de informações é proporcional à sua extensão, a identificação de um estrato específico, para uma intervenção, inserção, extração ou alteração na ordem de exibição, é potencialmente dificultada pela ausência de uma proposta de localização clara e percepção facilitada.

Conclui-se, portanto, que para iniciativas brasileiras que pretendem consolidação mercadológica com os recursos que têm disponíveis, há falta de instruções e modelos que reflitam acerca da pré-produção e a integre como material homogêneo, característica esta necessária para a adequada condução da narrativa transmitida como mensagem animada.

\section{DESENVOLVIMENTO}

O processo de produção de animação pode ser diferente em cada estúdio ao redor do mundo, segundo Wright (2005). Até mesmo em um mesmo estúdio, distintas demandas potencialmente resultam em diferentes métodos, pois diretores e produtores possuem suas próprias preferências para a produção da animação em que estão envolvidos. Ainda assim, apesar de cada projeto de animação possuir características peculiares, é possível identificar etapas-chave no 
processo de desenvolvimento de animação que orientam o fluxo de trabalho. Essas etapas foram identificadas e organizadas por alguns autores, como Byrne (1999), tendo o storyboard e o animatic como elementos centrais para a conclusão da préprodução e encaminhamento da obra à produção.

Winder e Dowlatabadi (2011) apontam que, antes de se tornar visual, a ideia inicial da obra é escrita em formato de roteiro. Para Comparato (1998), há uma compreensão cada vez maior por parte dos produtores que sem um material escrito não é possível dizer nada, uma vez que o que fica bem no papel fica bem na tela. E, apesar de que um bom roteiro não seja uma garantia de um bom filme, sem um bom roteiro não há um bom filme. Tal relação pode também ser feita à animação.

A estrutura básica de uma animação ajuda a escrever uma trama melhor, mas a diferença no tamanho do enredo faz a diferença na complexidade da estrutura do que será contado, conforme afirma Wright (2005). Ou seja, quanto maior a trama, maior será a complexidade da estrutura do roteiro - e, consequentemente, do storyboard e do animatic, aprofundando o desafio de identificação de um mesmo momento narrado nas três etapas que, embora distintas, são interdependentes qualitativamente.

Um notável problema, nesse sentido, é que roteiro, storyboard e animatic possuem modelos e formatos próprios de inserção e organização de seus conteúdos. No caso do primeiro, Byrne (1999) apresenta um modelo com instruções acerca de onde distribuir as informações e quais devem ser descritas, mas sem qualquer estratégia para divisão de cenas ou conexão da informação com o storyboard.

Normalmente em longas-metragens, o diretor costuma dividir o roteiro em sequências para distribuí-las aos artistas. Durante o desenvolvimento do storyboard essas sequências são subdivididas em shots sendo esses considerados a menor 
Projética, Londrina, v. 11, n. 2, p. 255-280, agosto 2020

unidade da produção de animação e que, integrados, irão compor a animação. O diretor costuma definir uma sequência a partir do local onde a ação irá acontecer e em qual horário do dia ela acontecerá, conforme Winder e Dowlatabadi (2011). Wright (2005) define cenas como unidades do roteiro. Cada cena contém um evento singular ou uma conversação entre personagens que ocupa um determinado período de tempo e local e faz com que a história de um passo a mais em direção a um clímax e/ou uma resolução/desfecho. Uma cena pode conter diferentes shots.

A forma com que as sequências ou cenas são identificadas e distribuídas na prática não é explicada nas referências bibliográficas pesquisadas para este trabalho. É possível inferir que as cenas são ordenadas pelo diretor, ou pelo responsável por fazer esse trabalho, com anotações sem um padrão sobre o roteiro impresso.

As tags de cor formam um índice das cenas definidas a partir de um roteiro. Ou seja, a partir do momento em que a ordem das cenas é definida, a aplicação das tags de cor para a identificação das cenas torna-se possível. O significado aplicado para cor foi o de identificar uma cena no storyboard e no animatic. No entanto, como ambos partem do roteiro e como é nele que as cenas são definidas, a aplicação das tags de cor deve ser iniciada no próprio roteiro, como exposto a seguir. 
Tags de cor para identificação de cenas animadas em roteiro... Animatic

Imagem 01 - Roteiro de episódio da série Nham Nham com tags de cor

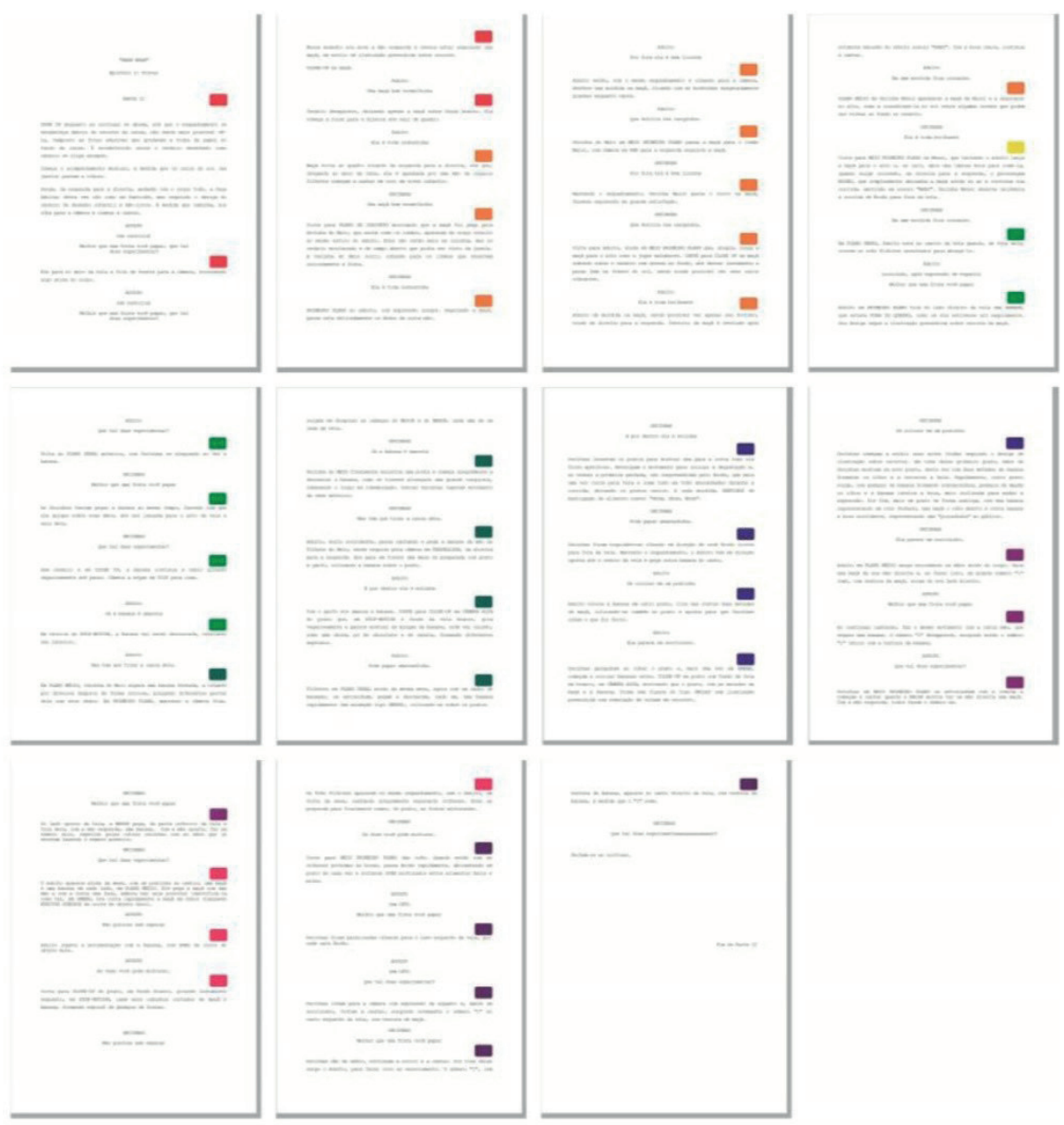

Fonte: Arquivo dos autores.

O roteiro exposto acima e utilizado como ponto de partida para o desenvolvimento e aplicação das tags de cor se trata de um videoclipe animado para um projeto em desenvolvimento no DesignLab, da Universidade Federal de Santa Catarina. As tags foram pensadas para ter o mesmo formato, tamanho e localização da extensão das cenas, alterando apenas a cor conforme uma nova cena era descrita. 
Projética, Londrina, v.11, n.2, p. 255-280, agosto 2020

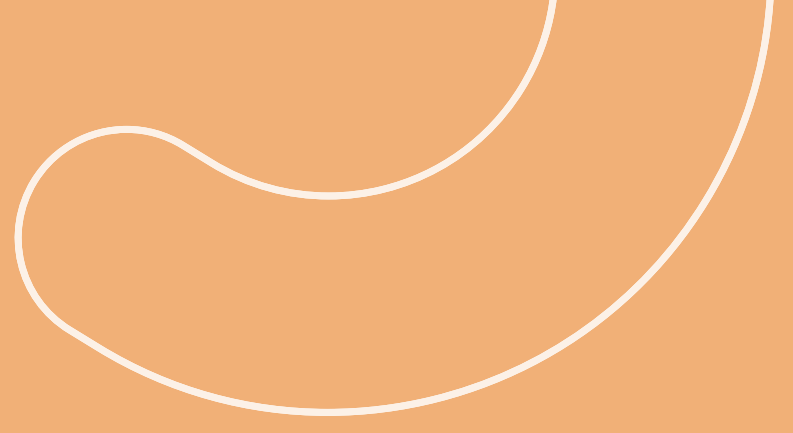

"Tanto o storyboard quanto o animatic são frutos de uma sequência de operações reiterativas e contínuas realizadas em conjunto pelos membros da equipe responsáveis por atuar nesses processos-chave, dentre eles diretor, roteirista, artistas e produtor. A lapidação de ambos só é possível devido à constante comunicação entre o grupo." 
Assim organizado o roteiro, pode ser iniciada a produção do storyboard, definido por Fowler (2002) como uma história em quadrinhos detalhada, deixando evidente visualmente do que se trata cada cena e o que ela retrata, pois não deve haver nenhuma dúvida visual ao olhar para os desenhos do storyboard. Se for necessário ler o que está acontecendo na cena para compreender, então o storyboard demonstra estar potencialmente inadequado e precisa ser refeito.

Storyboards são criados a partir de roteiros escritos e a quantidade de desenhos/painéis/quadros é relativa ao tamanho da animação e a quantidade de ações que acontecem numa sequência. Por exemplo, numa animação de um minuto, o storyboard pode conter cerca de doze desenhos ou quadros; já uma animação de vinte e dois minutos (episódios de série animadas, por exemplo) o storyboard pode conter mais de mil e quinhentos desenhos ou quadros; no caso de um longa-metragem (de, no mínimo, setenta minutos), o storyboard contém mais de três mil desenhos/quadros. Fowler (2002) afirma ainda que todos envolvidos na produção de animação desde o diretor, ao artista de layout, até o animador usam o storyboard. Entretanto, não existe uma regra a respeito de quantos quadros um storyboard deve conter, pois conforme afirmam Halas, Sito e Whitaker (2009) a quantidade de quadros desenhados está sujeito ao tipo do projeto e ao que ele contém. Dependendo da complexidade técnica da obra, o número de quadros pode variar, o que pode resultar em maior dificuldade entre um trecho do roteiro e seu equivalente no storyboard.

Não há, como apontado pelas pesquisas bibliográficas realizadas para este trabalho, um padrão para a diagramação e organização do storyboard, conclusão esta ratificada por Fowler (2002) ao afirmar não haver um modelo universal. Cada produção pode desenvolver seu próprio layout conforme as necessidades do projeto e da equipe. 
Projética, Londrina, v. 11, n. 2, p. 255-280, agosto 2020

Para White (2009) o processo de identificação de cenas e shots acontece da seguinte maneira: primeiro se lê e relê o roteiro muitas vezes para compreender bem a história evitando possíveis falhas de interpretação; a seguir se imagina cada ação, colocando algumas ideias em thumbnails (rascunhos que auxiliam uma pré-visualização); e então marca-se no roteiro onde cada cena ou shot começa e termina. Após fazer tais marcações no roteiro, são escritos os números das cenas nos desenhos para que a numeração dos desenhos siga de acordo com as cenas e shots feitas no roteiro. Há ainda a identificação da quantidade de ações de uma cena.

Exemplos pesquisados em Byrne (1999), Halas, Sito e Whitaker (2009) e White (2009) mostram que a identificação das cenas em storyboards é feita com números e escritos a mão pelo próprio artista que os desenvolveu. Essa fragilidade em comunicação não-sistematizada inspirou a criação das tags de cor, uma vez que a identificação das cenas, no que foi observado, não é voltada a ser realizada de forma rápida e fácil, podendo provocar confusão no entendimento e na interpretação do leitor, pois não existe um padrão visual quanto à localização das informações tal qual a forma que elas são expostas, além do agravante da dificuldade para compreender letras pessoais.

No material teste para o desenvolvimento deste trabalho, um episódio em formato de videoclipe animado da série experimental "Nham Nham", as tags de cor foram aplicadas com o propósito de ser a versão física exposta em sequência em parede visualização do projeto em sessões de pitching. O layout possui as seguintes informações: número do quadro, desenho, nome do projeto e identificação de cena, que no caso mostrado aqui, foi feito apenas com a tag de cor, mas também pode ser acrescentado o número da cena para completar a informação. 
Imagem 02 - Quadro de storyboard da série Nham Nham desenhado por Gabriela Z. Leal

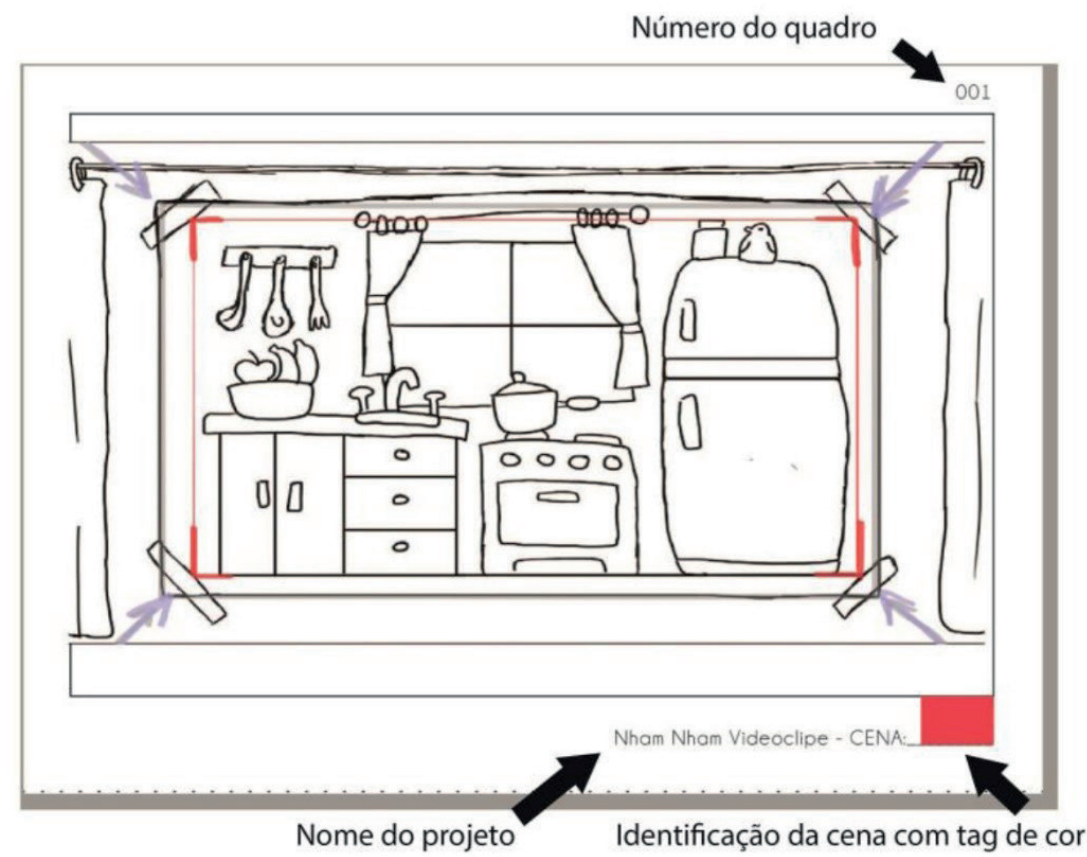

Fonte: Arquivo dos autores.

Com a trilha sonora e o storyboard concluídos, ou seja, todos os painéis do storyboard aprovados por diretores e clientes, a próxima etapa é construir o animatic ou story reel. Wright (2005) define animatic como uma série de painéis do storyboard ou outros desenhos que são digitalizados ou filmados com som para se aproximar da animação final. É um vídeo do storyboard que ajuda a testar a história e o tempo dela antes de gastar mais tempo e dinheiro com o projeto.

Na produção da animação, o animatic final aprovado é utilizado como base visual (template) de edição para editar a animação final, segundo White (2006). Ou seja, à medida que a cena recebe um novo tratamento, ela é utilizada para substituir sua versão anterior no arquivo de edição da animação. 
Projética, Londrina, v. 11, n. 2, p. 255-280, agosto 2020

Pesquisas exploratórias em materiais disponíveis em vídeos de making of (narrativas sobre processos e particularidades de produção audiovisual) de estúdios tradicionais de animação, encontrados tanto em canais de internet quanto em discos no formato DVD ou Blu-Ray, apontaram para falta de padrões na notação do tempo e equivalência de trechos com o storyboard e o roteiro. Quando há alguma identificação, ela é realizada por meio de números e letras, o que pode dificultar qualquer visualização de tais informações, uma vez que o animatic é reproduzido na velocidade (frame rate) do vídeo ou filme final (normalmente, de 24 a 30 quadros por segundo).

Existem ainda casos em que a informação não permanece em uma única localização da tela, variando entre os quatro cantos da tela (superior direito e esquerdo, e inferior direito e esquerdo).

Com o intuito de solucionar tais deficiências, as tags de cor para a identificação de cenas ou shots procuram minimizar o problema da legibilidade, principalmente aquele causado pela velocidade com que os quadros de filme ou vídeo (frames) são vistos e a variação da posição da informação na tela, visando facilitar a compreensão da informação e o foco naquilo que deve ser o ponto da atenção de quem está recebendo a informação.

Ao contrário dos números que mudam a cada frame, a tag muda a cor somente quando uma nova cena é exibida, permanecendo na tela não somente em um frame, mas durante todo o tempo em que a cena fica no ar, que pode ser por segundos ou a minutos. Além disso, um único posicionamento da tag durante todo o animatic possivelmente guia o olhar quando necessário procurar a cor que identifica a cena.

Pretendendo evidenciar a tag (posicionada no canto inferior esquerdo), o formato do animatic, no experimento, foi alterado para que não ocupasse uma tela 
cheia de televisão (de padrão Full HD, ou seja, 1920×1080), mas que ficasse dentro de uma moldura preta. Assim, a tag de cor foi aplicada não acima dos frames do animatic, mas abaixo deles em contraste com o fundo preto.

Imagem 03 - Tela do animatic da série Nham Nham, desenhado por Gabriela Zanella Leal

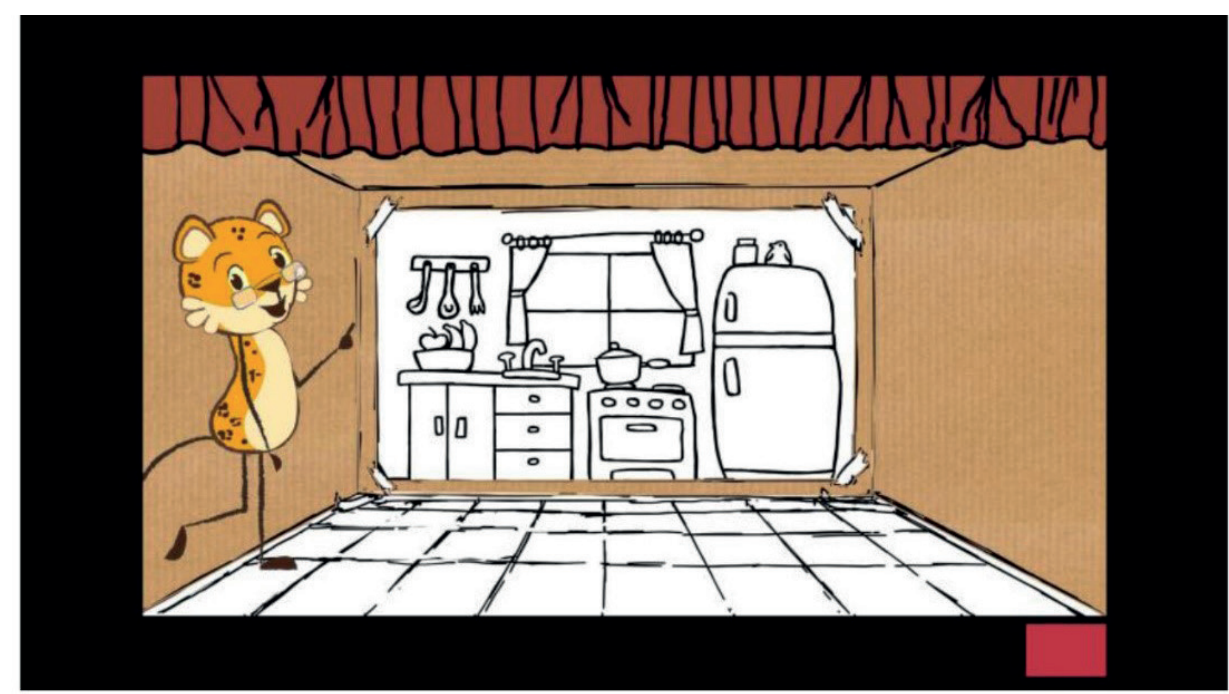

Fonte: Arquivo dos autores.

Foram conectados, de forma padronizada por cor e posicionamento da tag, todos os trechos que se correspondem entre roteiro, storyboard e animatic, cuja identificação de cor em um, leva à localização do estrato às suas aplicações nos demais recursos descritos de pré-produção.

\section{APLICAÇÃo}

A identificação de cenas e shots, conforme concluído pela análise dos autores mencionados anteriormente, costuma ser feitas por meio da escrita de próprio punho do(s) artista(s) que desenvolve(m) o storyboard e o animatic, 
Projética, Londrina, v. 11, n. 2, p. 255-280, agosto 2020

independente do layout utilizado. E, para tratar comentários, ajustes e alterações em cenas e shots no storyboard e no animatic, a legibilidade das informações específicas pode não ser adequada para uma rápida comunicação, potencialmente provocando dúvidas devido à caligrafia, ao tamanho que a informação foi escrita, à distância que está sendo vista, além da velocidade com que cada frame passa na tela durante a exibição do animatic.

Presume-se ser possível identificar uma tag de cor a uma distância maior do que o número e/ou a letra. Isso pode facilitar a compreensão e identificação das cenas pela equipe envolvida com o projeto de animação, tanto durante os encontros para pitching quanto para outros momentos onde, devido a alterações ou revisões, seja necessário encontrar trecho equivalente em qualquer uma das etapas da pré-produção.

A cor, neste trabalho, foi empregada visando o sentindo psicológico dado a ela e não o simbolismo que cada uma possivelmente carrega, ou seja, o significado empregado nas cores aqui foi estritamente o de identificar as cenas e os shots.

Bastos, Farina e Perez (2006) apontam que a cor constitui um evento psicológico, sendo que o termo cor é equivalente à expressão cor-luz. Pedrosa (2009) dividiu em dois grupos os estímulos que causam as sensações cromáticas: o das cores-luz e o das cores-pigmento. O primeiro se trata de emissão cujas matizes somadas formam o branco. O segundo de materiais que, de acordo com características próprias, refletem os raios luminosos.

Os dois estímulos visuais formados pelas cores-pigmento são as corespigmentos transparentes (por exemplo: películas fotográficas, impressões gráficas e aquarelas) e as cores-pigmento opacas (como encáustica, óleo e têmpera), ainda segundo Pedrosa (2009). Portanto, é válido afirmar que este experimento fez uso dos seguintes estímulos visuais: cor-pigmento transparente e cor-pigmento 
opaca. A primeira foi aplicada no meio digital, mais precisamente nas tags de cor do animatic e na última versão digital do storyboard. Já a cor-pigmento opaca foi aplicada nos painéis de storyboard expostos em sequência na parede do Designlab (conforme imagem abaixo). Nesse caso, as tags de cor foram feitas com recortes de papéis coloridos industrialmente com cor-pigmento opaca.

Apesar da indeterminável possibilidade de aplicação de cores, neste trabalho foram aplicadas algumas tendo em vista que a duração da animação, que é de aproximadamente dois minutos, contendo nove cenas.

A base para a seleção das cores aplicadas nas tags foram as cores primárias (vermelho, amarelo e azul), cujas aplicações foram feitas para identificar cenas que marcam transições do videoclipe da série "Nham Nham". As secundárias (laranja, verde e violeta), assim como as terciárias (vermelho laranja, amarelo Iaranja, amarelo verde, azul verde, azul violeta e vermelho violeta) também foram empregadas.

Desta forma, foi estabelecido: Cena 1 representada pelo vermelho; Cena 2 representada pelo laranja; Cena 3 representada pelo amarelo; Cena 4 representada pelo verde; Cena 5 representada pelo azul verde; Cena 6 representada pelo azul; Cena 7 representada pelo violeta; Cena 8 representada pelo vermelho violeta; Cena 9 representada pelo azul violeta.

As terciárias vermelho laranja, amarelo laranja e amarelo verde não foram empregadas, pois o número de cenas que as tags foram aplicadas foi nove enquanto o número de cores no círculo cromático aqui utilizado como base foi doze. 
Projética, Londrina, v. 11, n. 2, p. 255-280, agosto 2020

\section{CONSIDERAÇÕES FINAIS}

Este experimento desenvolveu e aplicou tags de cor para facilitar a identificação de cenas no storyboard e no animatic do videoclipe animado da série "Nham Nham". As tags foram criadas a partir da determinação de cenas no roteiro com o propósito de tornar a comunicação dos envolvidos com a animação mais clara, fácil, rápida e com menos erros de interpretação e de identificação durante os processos de desenvolvimento do storyboard e do animatic.

As tags de cor apresentam potencial de uso e aplicação em projetos de animação, uma vez que normalmente o storyboard e o animatic são exibidos em uma sala para um grupo de pessoas envolvidas com o projeto, e essas pessoas não necessariamente ficam próximas aos quadros de storyboard pregados na parede, ou à tela em que o animatic é exibido.

Ainda assim, há fatores e questionamentos a respeito de suas aplicações que demandam aplicações e pesquisas futuras para comprovar sua eficiência e eficácia. Por exemplo, o fato de um círculo cromático possuir doze cores e o número de cenas em um roteiro pode ser maior ou menor que esse número, levando à reflexão sobre métodos de adaptação e seleção de cada cor para determinada cena. Além disso, é necessário mensurar a média de quais as distâncias entre observador e tag em contrapartida à notação numérica manual ou impressa a cada divisão de cena.

Percebe-se também que é necessário um estudo de equivalência visual entre a cor emitida na tela, para o animatic, e a refletida em papel no storyboard e no roteiro quando impressos.

Por fim, conclui-se que o próximo passo do experimento é realizar testes comparativos entre equipes que utilizam e que não utilizam as tags de cor para 
registrar dimensões relacionadas à eficiência em prazos, recursos e integração de seus membros quando expostos a cada proposta.

Com tais observações e reconhecimento das limitações, pretende-se com este artigo que estudantes e profissionais da animação possam pensar os métodos de forma a transformá-los, refletindo suas alternativas de produção a fim de encontrar alternativas congregadoras que evitem custos extras ao impedir, como no exemplo deste texto, que uma alteração em qualquer etapa resulte um gasto de tempo ao tentar encontrar uma mesma descrição de ação em documentos diferentes e sem um padrão de notação que estabeleça uma ligação explícita entre eles.

Diante das oportunidades legais e oriundas do poder público para recursos financeiros de produção e para exibição, economia de tempo e sistematização padronizada da informação podem ser formas de impedir gastos extras e permitir realocação de valores monetários para outras possibilidades que favoreçam a qualidade da produção.

Tendo em vista o quadro brasileiro de aumento de lançamento de obras, iniciativas como a proposta pelo presente artigo, ao não eliminar ou acrescentar etapas - mas ponderar acerca de seu design - podem representar compensações estratégicas às diferenças de investimento para execução das obras em relação às contrapartidas estrangeiras. 
Projética, Londrina, v.11, n.2, p. 255-280, agosto 2020

\section{REFERÊNCIAS}

1. BASTOS, Dorinho; FARINA, Modesto; PEREZ, Clotilde. Psicodinâmica das cores em comunicação. 5. ed. São Paulo: Edgard Blücher, 2006.

2. BEANE, Andy. 3D animation essentials. Indiana: John Wiley \& Sons, 2012.

3. BRASIL. Ministério da Cultura. Brasil lança maior número de animações em 22 anos. Brasília, DF: Ministério da Cultura, 2018. Disponível em http://www. cultura.gov.br/noticias-destaques/-/asset_publisher/OiKX3XIR9iTn/content/ brasil-lanca-maior-numero-de-animacoes-em-22-anos/10883. Acesso em: 25 set. 2018.

4. BYRNE, Mark T. The art of layout and storyboarding. Leixlip: Mark T/Byrne Publication, 1999.

5. COMPARATO, Doc. Da criação ao roteiro. Rio de Janeiro: Rocco, 1998.

6. FOWLER, Mike S. Animation background layout: from student to professio nal. Miramichi: Fowler Cartooning Ink, 2002.

7. FRANCIS, Glebas. Directing the story: professional storytelling and storyboarding techniques for live action and animation. Burlington: Focal Press, 2009.

8. HALAS, John; SITO, Tom; WHITAKER, Harold. Timing for animation. 2. ed. Burlington: Focal Press, 2009.

9. HART, John. The art of the storyboard: a filmmaker's introduction. Burlington: Focal Press, 2008.

10. JONES, Angie; OLIFF, Jamie. Thinking animation: bridging the gap between $2 d$ and CG. Boston: Thomson, 2007.

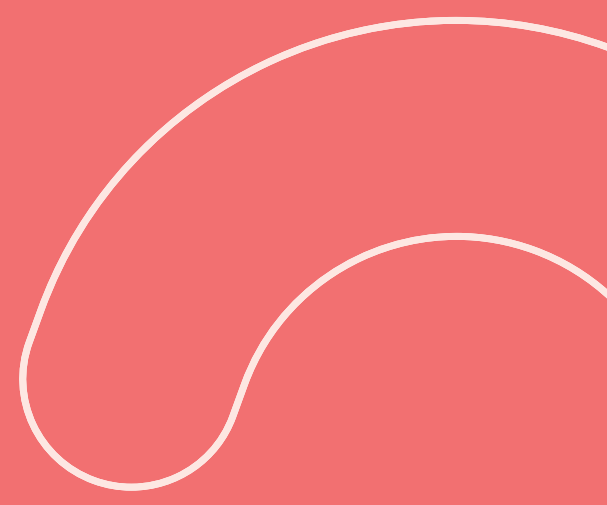


Tags de cor para identificação de cenas animadas em roteiro... Animatic

CARDOSO, C. et al

11. KUNDERT-GIBBS, John; KUNDERT-GIBBS, Kristin. Action! Acting lessons for CG animators. Indiana: John Wiley \& Sons, 2009.

12. MARX, Christy. Writing for animation, comics, and games. Burlington: Focal Press, 2007.

13. O'HAILEY, Tina. Hybrid animation: integrating 2D and 3D assets. Burlington: Focal Press, 2010.

14. PARENT, Rick. Computer animation: algorithms and techniques. San Francisco: Morgan Kaufmann Publising, 2002.

15. PEDROSA, Israel. Da cor a cor inexistente. 10. ed. Rio de Janeiro: Senac Nacional, 2009.

16. PURVES, Barry J. C. Stop motion: passion, process and performance. Burlington: Focal Press, 2008.

17. ROBERTS, Steve. Character animation fundamentals: developing skills for $2 d$ and 3d character animation. Burlington: Focal Press, 2011.

18. SHAW, Susannah. Stop motion: craft skills for model animation. Burlington: Focal Press, 2004.

19. TEIXEIRA, Júlio Monteiro. Gestão visual de projetos: um modelo que utiliza o design para promover maior visualização ao processo de desenvolvimento de projetos. 2015. 330 f. Tese (Doutorado em Engenharia de Produção) - Universidade Federal de Santa Catarina, Florianópolis, 2015. 
Projética, Londrina, v.11, n.2, p. 255-280, agosto 2020

20. THOMAS, Frank; JOHNSON, Ollie. The illusion of life: Disney animation. New York: Disney Editions, 1981.

21. VAUGHAN, William. Modeling. Berkeley: New Riders, 2012. Digital.

22. WEBSTER, Chris. Animation: the mechanics of motion. Burlington: Focal Press, 2005.

23. WHITE, Tony. Animation from pencils to pixels. Burlington: Focal Press, 2006.

24. WHITE, Tony. How to make animated films. Burlington: Focal Press, 2009.

25. WHITE, Tony. The Animator's workbook: step-by-step techniques of drawn animation. New York: Watson-Guptill Publications, 1988.

26. WINDER, Catherine; DOWLATABADI, Zahra. Producing animation. 2. ed. Burlington: Focal Press, 2011.

27. WRIGHT, Jean Ann. Animation writing and development: from script development to pitch. Burlington: Focal Press, 2005.

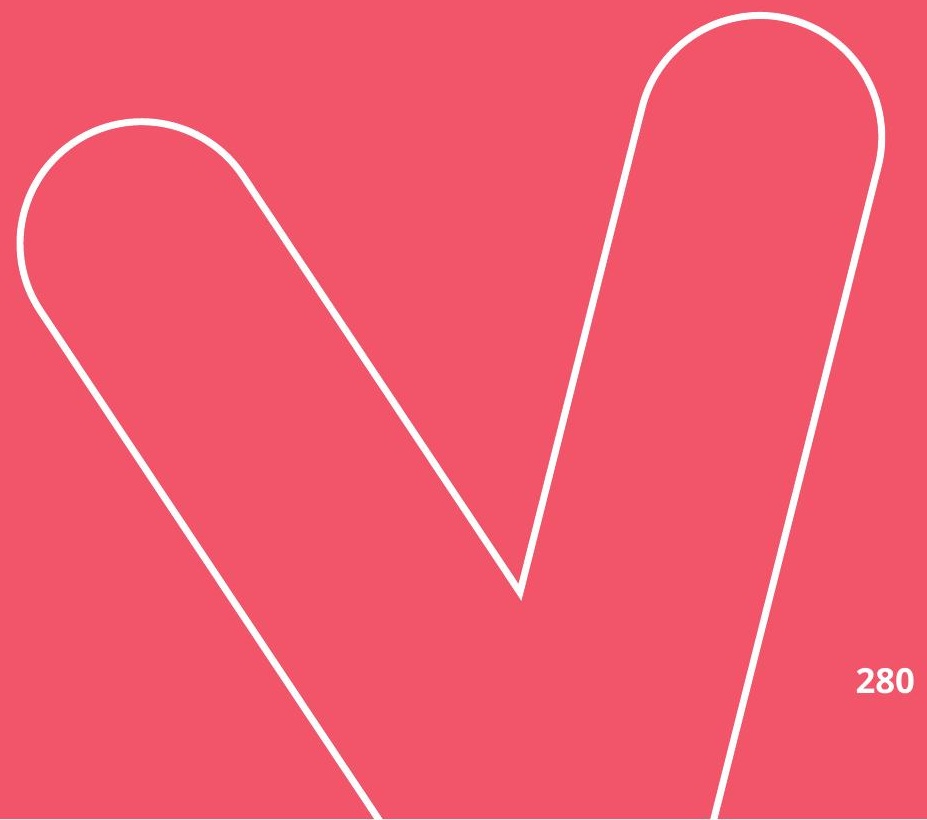

